\title{
Investigating Social Factors Associated with Emotional Labor Among Nurses (Case Study; Tehran West Region Hospital's)
}

\author{
Akbar Talebpour \\ Ph.D Candidate of Sociology, \\ University of Isfahan, Isfahan, Iran \\ E-mail: talebpour110@yahoo.com \\ Ali Rabbani Khurasghani \\ Associate Professor of Sociology, \\ University of Isfahan, Isfahan, Iran. \\ E-mail: a.rabbani@ltr.ui.ac.ir \\ Vahid Ghasemi \\ Associate Professor of Sociology, \\ University of Isfahan, Isfahan, Iran. \\ E-mail:v.ghasemi@Itr.ui.ac.ir
}

Doi:10.5901/mjss.2013.v4n4p369

\section{Abstract}

\begin{abstract}
This study has investigated the emotional labor and it's effective factor's in Tehran West region hospitals, The sample consisted of 315 nurses working at the hospitals, Erfan, Ibne- Sina, Imam Khomeini, Jam, Mostafa Khomeini, payambar, Sarem and sherkate naft. 67 percent of the respondents were women and the rest of them were men. In this study emotional labor is measured by two dimensions: surface acting and deep acting. This two dimensions are covered by 13 items. Factor analysis of questionnaire items indicates a good construct validity of the measurement instrument and reliability of questionnaire items which extracted by Cronbach's alpha was suitable. The effect of each independent variable on the dependent variable was measured by using regression model. All independent variables were accounted for about 66 percent of the variability, but the remaining 34 percent were not explained by the regression model. The results showed the emotional labor of the nurses is above the average level and deep acting was more than surface acting. Job autonomy has the most positive impact on increasing emotional labor where as jobs hierarchy systems has the most negative impact on doing emotional labor. The results of the study also shows, hospital expectations oblige the nurses to perform duties which their job responsibilities and do not expect them to do emotional labor.
\end{abstract}

Keywords: Emotional Labor, Surface Acting, Deep Acting, Hospital Expectations, Multiple Regression Analysis, Factor Analysis

\section{Introduction}

Emotional labor introduced by American sociologist, Arlie Russell Hochschild by the first time in 1979 and then attracted a lot of interest among sociologists. Emotional labor is a form of emotional regulation wherein workers are expected to display certain emotions as part of their job, and to promote organizational goals. The intended effects of these emotional displays are on other, targeted people, who can be clients, customers, subordinates or co-workers (Grandey,2000) According to Hochschild, jobs involving emotional labor are defined as those that:

A. Require face-to-face or voice-to-voice contact with the public.

B. Require the employee to produce an emotional state in another person (client or patient).

C. allow the employer, through training and supervision, to exercise a degree of control over the emotional activities of employees. ( Hochschild ,1983)

According to Hochschild an employee adjusted his feelings based on his job expectations. She distinguishes between two types (surface acting \& deep acting ) of emotional labor. She uses the term of surface acting in order to the regulation of actions in face to face interaction, in this situation the person does needed feeling just as a reaction to the actions of 
others (eg, smiling in front of an angry person), and she also uses the term of deep acting for the regulation of action's which help to produce specific emotions, in this situation, a person tries to change the job requirements based on his/her inner feelings (eg, hide their anger or express it is not a problem at situation of high customer concern)(lbid, 19). In other words, surface acting involves an employee's presenting emotions on his or her "surface" without actually feeling them, the employee in this case puts on a facade as if the emotions are felt, where as in deep acting employee's modify their inner feelings to match the emotion expressions the organization requires.

It is worth mentioning here that Hochschild noted that the purpose of emotional labor is simply trying to change the amount and quality of emotional feeling and success or failure of an employees, it does not do anything with ability in expressing his emotions. The person here somehow manages his/her emotions which this management may be successful or unsuccessful, but the persons attempt to change his emotion is sufficient, and the failure actions of emotional management are still count as emotional labor. (Hochschild 1979,13)

Generally emotional labor refers to evoking special emotions and suppressing other feelings. In other words, a person sometimes evokes specific emotion which is positive, and sometimes suppresses specific emotion which is negative (Ibid). It should be noted that Hochschild avoid the use of manipulating emotions and use the term of change instead of it (lbid,10)

In fact unlike Freud, the purpose of Hochschild was that show how people consciously and not unconsciously feel, and unlike Goffman to show how people try to feel, and not how they appear to feel. Hochschilds early work, the stewardess jobs was listed directly but in later works, other people emotional labor like nurses, medical staff, lawyers and so on was noted by Ashforth\& Humphrey, Grandey, feldman and others. In recent years the concept of emotional labor and its impact on staff, has gain a lot of attention and many researchers has concentrated on the effects of emotional exhaustion, job satisfaction or other effecting impact's on the effects of emotional labor. (Glomb et al 2004,9)

With increasing interest of sociologists and psychologists to study different aspects of emotional labor, among nurses and hospital staff, studies in this area has increased in size as different approaches have been introduced in the scope of emotional labor. Unfortunately, however, they aren't in sociological and even psychological work in this respect in Iran. The lack of such studies may lead to unwanted problems in the health care system and treatment on the one hand, and the negligence of nursing staff problems on the other. However, existence emotional labor studies connected with the nursing staff in the world and the lack of such studies in Iran, we decide to do a scientific research in this respect. Two aims is observed for this work; first, evaluating of main issues in this field and the other is opening the way for the future studies. This paper examines the social factors associated with the emotional labor among nurses in Tehran (case study: Tehran West Region Hospitals) and deals with the strategies to increase the emotional labor, by Using multiple regression analysis, we try to measure emotional labor dimensions and its impacting factors via following purpose:

1- Which extent of emotional labor exist in target society?

2- which factors in doing emotional labor are the most effective?

3- what is the practical means to increase emotional labor among nurses?

\section{Literature Review}

Since the concept of emotional labor has created in 1983 by Hochschild, four main approaches can be differentiate on the literature of emotional labor, this approaches are the followings:
1- Hochschild Approach 1983.
2- Ashfoeth \& Humphrey Approach 1993.
3- Morris \& Feldman Approach 1996.
4- Grandey Approach 2000.

All of the above approaches agree with the fact that managing of emotion act is an important aspect of emotional labor and organizational rules as a guide to presenting emotions. In addition all four perspectives, have been aware of individual and organizational outcomes associated with emotional labor, But however there are important differences among the four perspectives, in the result there is not a complete approach in this area and most of the researchers to measure the emotional labor, use combining of these perspectives. In addition to the above approaches, in the present work, the concept of social conceptualizing of Turner also being used as fifth approach, However, Turner's approach is not paid directly to emotional labor and we want to combine this approach with previous ones . 
Hochschild Approach (1983):

Hochschild as founder of the concept of emotional labor, in her famous book the "Managed Heart" presented the management of employees emotions in the organizations by the first time. She raised the concept of emotional labor as emotional management, establishing general and provides a visible image of the body to receive the wages. Hochschild argued, managing emotions, sometimes was occurring mainly in the private atmosphere life but today it has become a large part of people working life, and many organizations are demanding, emotional rules, as job requirements, such organizations want smile and customer satisfaction for good service to its customers.

In Hochschild view, when organizations are involved in management of individuals a variety elements separated from peoples and institutional mechanisms are replaced whit them, the action place moves from managing feelings to the position of organization, according to traditions and institutional rules many peoples and objects are combined with each other to perform actions. Organization officials believe that they make assumptions that employees develop good feelings or when employees feel that their parameters can be centered around memory, people are doing things better. These employees are not allowed to see and think as they like, it is only necessary to show emotions (surface acting) in ways that confirm the institute. In addition, some organizations skillfully deep acting techniques can recommend, They propose to their employees how imagine and consequently how they feel, as a farmer close blindfolded on his horse to take it where he wants, institutions can control how employees feel.

To The Hochschild, emotional labor may leads to negative emotions such as; stress and job burnout. She sees the emergence of emotional dissonance as cause of this negative results, that occurs when a person show emotions which is inconsistent with real feeling. Primary emotional dissonance is associated with surface acting that staff should change their appearance, not their real feelings, furthermore, the emotional dissonance, is an attempt to prove that the job is used to regulate emotions, these efforts may have adverse effects on employees. Negative results of emotional labor on the attendants and ticket collectors have been done by Hochschild in a qualitative study has shown, it may result in feeling like substance abuse, headaches and Absenteeism.

However, Wharton (1993) found there is no significant relationship between Hochschild model of emotional labor and emotional exhaustion, but there is a high correlation between job satisfaction and emotional labor; those who felt their job has high emotional burden were less expressed job satisfaction from that people once felt less emotional burden on their jobs.

To the Hochschild opinion, when feelings are successfully commercialized, employees do not feel alienated or fraud, and somewhat aware of their personal service that really how it is, ones feel satisfy, in doing this job deep acting help to the employees, and is not the source of discouraged, but when the general process of sentiment commercialization split in its internal elements, viewing the job, becomes a waste of life, in this situation, occurs emotional withdrawal from the job, and responsibilities of individuals are used as a means of showing reluctance or willingness to do anything to hide their transmutations (Ibid,138).

Generally according to Hochschild when staff performing emotional labor, they choose three different perspectives or modes, that each of them has its own risks. In the first case the employee does not make sense of separation between himself and his job ; such a person is faced with the risk of burnout, this person may be considered the institution and serves as part of his/her self, therefore, knows any defect in the Service caused by his/her weakness, such a person do not depersonalized from job process .

In the latter case, the employee make a clear distinction between himself and his work, so the person does not suffer burnout, but such a person can be blamed himself for creating this distinction and his artificial behavior, and this work increases the risk of job.

In the third case, an employee in addition to make a clear distinction between himself and his work is recognized, he does not blame himself, but knows this due to the nature of the work does not, in this case, there is a risk of disappointment to be encountered.

\section{Ashfoeth \& Humphrey Approach (1993):}

Ashfoeth \& Humphrey (1993) were introduced emotional labor as showing expected emotions during the service interaction. Similarly to Hochschild work, these authors stated that, emotional labor may represent kind of employees management as an attempt to visualize the specific receiving themselves to others. Ashfoeth \& Humphrey agreed that in doing emotional labor, employees should do sometimes surface-acting and sometimes deep-acting, in order to represent expected feelings. They added a third step, that goes beyond the surface-acting and deep-acting, help to the complete definition of emotional labor, Ashfoeth \& Humphrey named this third step as genuine acting. The third step, is related with 
the possibility of pure experience spontaneous employees and show good feelings to this experience, for example, a social worker may be really, deep sympathy with children who abused, and therefore does not make any surface or deep interactions.

Ashfoeth \& Humphrey observed that every person, regardless of organizational objectives may show genuine acting as emotional labor display, in appropriate circumstances. They also discussed the role of effort in emotional labor, and believed; surface and deep acting can be coupled with efforts to try on, but in some cases (due to the repetitive nature of many of the habits and interactions), this strategy may become a routine procedure and repeated process without trying . Accordingly, Ashfoeth \& Humphrey stated: If a feel is pure and some of emotional labors do not need to attempt to show the certain emotions, showing such feelings have less workload and less negative impact on the employees.

The main important of Ashfoeth \& Humphrey theories, is their emphasis on visible expression of feelings and emotions rather than internal management. Thus, although they were investigated surface and deep acting activity but they focus on the results of this process, instead of their process. They focused on the role of efforts in explaining surface and deep acting and are oblivious the effect of this work to the customers, Due to the lack of emotional labor role in the pure sense of the customers, is considered key weaknesses of Ashfoeth \& Humphrey approach. Ashfoeth \& Humphrey have argued that emotional dissonance is deeply relevant concerned service providers about the welfare of the client. As deep action requires a greater degree of effort, when a service provider is concerned about the welfare of the clients may use appropriate techniques of feel for producing deep and sincere service. In contrast, if the service provider is not concerned about their customers, it is possible to use the surface acting to deal with them. As a result, people with high levels of empathic concern, use the genuine acting and true emotions at work. Even when the real and pure answer is difficult, those with high empathic concern will be used deep acting to generate appropriate feelings and responses. In both situations, the incidence of emotional dissonance for such people is very unlikely. (Ashforth\& Humphrey1993, p88115 )

However Ashfoeth \& Humphrey emphasized that emotional labor, when was difference between the feeling feels and expected emotions, may be lead to emotional dissonance and alienation. But largely are emphasized on positive emotion results, such as, efficiency, and self-expression.

\section{Morris \& Feldman Approach 1996:}

Morris and Feldman (1996) defined emotional labor as "the effort, planning, and control needed to express organizationally desired emotion during interpersonal transactions" (Morris \& Feldman ,1996,987) .Unique feature of the emotional labor theory of Morris and Feldman, is the emphasis on the role of effort. Unlike Ashfoeth \& Humphrey they argue that even in the situation which there is no any difference between employee feels and organizational rules, Still we should not sure that the emotion is shown properly based on organizational manner. According to Morris and Feldman theory, fit any kind of emotional reaction is defined largely by environmental factors. Based on their theory many of workrelated factors, such as, being explicit (explicit), procedural rules and a general sense of duties, do affect emotional labor. Morris and Feldman focuses on the following four properties of emotional labor:

1. frequency of emotional labor,

2. attentiveness (intensity of emotions, duration of interaction).

3. variety of emotions required.

4. emotive dissonance (the difference between felt emotions and expressed emotions) ( Ibid).

Morris and Feldman suggest that, increasing the all of four dimensions of emotional labor, lead to higher emotional burnout, but the emotional dissonance, only has an impact on job satisfaction. Morris and Feldman Besides these four, suggest many personal variables, job characteristics, and organizational characteristics that may be prior to emotional labor Individual differences include variables such as; sex and negative and positive interests, job characteristics, including factors such as ; routine work procedures and job autonomy, and organizational characteristics include variables such as; clear display rules, and extent of supervising of supervisors. Morris and Feldman (1997) tested part of their proposed models, in this study, they conceptualized emotional labor, repeated interaction, and the interaction term and emotional dissonance. They found that, routine work procedures, have positive correlation with repeated of emotional labor and emotional dissonance, and a negative correlation with the interaction term, the position of the recipients, have a positive correlation with repeated interaction and was found negatively related to coordination between job autonomy and emotional dissonance, among emotional labor dimensions, emotional dissonance have maximum variance in the results of emotional labor, it was a positive relationship with emotional exhaustion and was negatively associated with job satisfaction ( Morris\& Feldman,1997 ). 


\section{Grandey Approach 2000:}

Grandey (2000) are defined emotional labor as a process of emotional regulation and expression of feelings in order to achieve organizational objectives. He was inspired by the Hochschild work, suggested that, the regulation of emotions, is including surface acting (the visible manifestations of emotion) and deep acting (the felt emotions). This conceptualizing of emotional labor, offers something more than an internal feeling approach, by focusing on Hochschild job category, visible effects of Ashfoeth \& Humphrey, or situational characteristics and emotional dissonance of Morris and Feldman . In addition, Grandey combined models of Hochschild, Morris and Feldman, and offer an integrative model , for example he argued ; job characteristics such as; frequency, duration and diversity that defines much of Morris and Feldman models of emotional labor, may be are an arrangements of emotional labor, Furthermore, the experience of visible emotions as a part of the definition of Ashfoeth \& Humphrey likely to performance goals of emotional labor, that are considered among loyal consumers as future goals ( Grandey:2000).

According to Grandey, deep acting is argued to be associated with reduced stress and an increased sense of personal accomplishment; whereas surface acting is associated with increased stress, emotional exhaustion, depression, and a sense of inauthenticity (Grandey,2003).

Grandey model of emotional labor are include, situational factors, individual factors and organizational factors; Situational factors of emotional labor, is including expectations Interactive (consisting of frequent, duration and diversity rules of engagement as provided) and emotional events (positive and negative events), individual factors, are including gender, emotional expression, emotional intelligence and emotional being, organizational factors is including job autonomy, supervisor supports and staff supports . Grandey is determined, burnout, job satisfaction, job performance and withdrawal behavior as a result of emotional labor.

5-2- Jonathan .H.Turner Approach 2005:

In recent work reviewing dramaturgical and cultural theorizing on emotions, Turner and Stets (2005) highlighted the work of Goffman $(1961,1983)$, Hochschild $(1979,1983)$, Rosenberg $(1990,1991)$, Thoits (1990), and Clark (1997) to development the sociology of emotions. (Turner\& Stets:2005p2). Turner according to the ideas of Darwin (1872), Plutchik (1962.1980.2002), Kemepr (1987) and others about the universality of basic emotions, have dividing them in to range of low, medium and high degree. He categorized this emotions in one continuum

as satisfaction - happiness, aversion - fear, assertion - anger , disappointment - sadness. According to Turner classified, the intensity of each of the primary emotions, they cause people to be secondary emotions, for example, disappointment - sadness continuum caused to resign. The classification of secondary emotions is the most important categories in this field and is consistent whit Kempr and Plutchik attitudes; about combining primary and secondary emotions. According to Turner, the emotional reaction of people upon to the positive and negative expectations and penalties in different conditions is vary. According to him, people on the basis of defensive mechanisms, punishment, positive and negative expectations via socio-cultural engage in emotional labor. In addition to the above characteristics, Organizational Characteristics

like; the size of unit, integrity of boundaries, formality of structure, explicitness and scope of horizontal division of labor, explicitness and scope of vertical division of labor, and Organizational Categorizing System such as; homogeneity of members in unit, discreteness of features defining membership , differential value or rank of categories,

correlation among categoric units, correlation of categoric units with division of labor in corporate units, are important in display emotions.( Turner\& Stets:2006,289)

\section{Emotional Labor and Nursing:}

The concept of emotional labor in nursing suggested first time by Smith (1992) that he study, the quality of nursing and nurses' experiences in particular sections. In this study nurses, have clearly described the experiences of themselves, patients, partners and events, it seems that in this study emotional response to those events by the characters, expectations and personal appearance which has observed events personally, has been studied. Nurses tend to be involved in a position of job-based opportunities and encourage was diversity. Nurses have raised descriptions on how to overcome their various situations and events through proverbs. In another study, Henderson (2001) studied trends in nurses 'involvement or abdicating their customers and the impact of both of these two approaches in the nurses' is investigated. According to this study was indicated that there are the relationship between nurses individual will and skill to be flexible about the value of their reactions to the withdrawal of care against involved in patient care. Flexible nurses, were more valuable emotional connections made with the patient. The background and characteristics of a particular patient, can the nurse encourages a certain level of emotional involvement between patient and nurse or will prevent it. 
Not only nurses emphasized the role of emotional engagement in treatment, but also emphasized the need for the emotional detachment. ( Henderson: 2001:,130 - 138)

Role of performance emotional labor in the workplace, depends on the employer organizations about the rules of the show feel, Diffen dorf (2005) reported that the rate of emotional involvement in emotional labor, in addition to organizational rules, depending on their level of commitment to follow the rules are different.

Ericsson (2001) reported that, men fewer than women are engage in deep acting and nurses of color fewer than white, are show the expected emotions.( Rafaeli, A., \& Sutton, R. :1987) Ericsson and Ritter (2001) portraying the relationship between emotional labor and it negative results showed; excitement emotion management is related with high levels of burnout ,estrangement and inauthenticity.( Erickson \& Ritter:2001,Krummel \& Geddes:2000). Brotheridge and Grandey (2002) showed that pretend to feel at work, relevant with the accomplishment diminish . Finally, Mann (2004) summarized the negative consequences

of emotional labor to include lowered self-esteem, cynicism, and job turnover. More recently, researchers have focused on positive outcomes of work related emotional labor. Examples have included a sense of personal accomplishment (Brotheridge and Grandey 2002); maintaining objectivity and emotional equilibrium (Mann 2004); lower turnover and better work performance (Meier et al. 2006); higher work satisfaction (Bulan et al. 1997; Conrad and Witte 1994); increased task effectiveness on the job (Ashforth and Humphrey 1993); increased sense of community (Shuler and Sypher 2000); and tangible benefits like increased tips and selling of product(s) (Rafaeli and Sutton 1987).

Some variables in different studies, have been identified that changes in them used to increase positive emotions this variables include followings: Potential moderators of these relationships include social support (Brotheridge and Lee 2002), situational, interpersonal, and individual factors (Ashforth and Humphrey 1993), role identity (Mann 2004), opportunities to decompress (Montgomery et al. 2006), job autonomy (Lewis 2005; Wharton 1993), and the freedom to express emotion (Lively 2000). A discussion of the differences between the fields of nursing and other jobs, related whit this job position and duties of the profession in a hospital, so that that interacting with patients is not part of a nurse's 'legitimate' work (also see Henderson 2001; Smith 1992).

For example, in her study of hospice workers, James $(1989,498)$ observed that after sitting and talking to a patient, a nurse might say 'I must go and do some work now'. Another thing about the nurses working there is that, on the one hand, nurses are faced with patients who have little knowledge of medicine, and doctors are faced with the other hand, those who like show their craft, this fact leads to double behavior in the nurses. According to these fact Nursing's is more 'precarious' professional position is not likely to be improved through nurses' embracement of medicine's emotional culture of 'detached concern' - a set of cultural prescriptions that reinforces the institutionalized separation of rationality and emotion while appearing to combine them (Erickson et al,2008,722)

Davies (1995), Gordon(1991), Herdman (2004), have noted, nurses themselves are not totally comfortable with what it would mean to fully recognize the emotional skill required in their jobs (Phillips 1996), Also nurses working within a masculinized context that simultaneously devalues the knowledge and skill underlying the performance of emotion management (Gordon 1991; Phillips 1996; Staden 1998; Woodward 1997).

Generally, modern health care operates in a highly scientific and technocratic society and involves increasing use of high technology equipment and drugs in prevention, diagnosis and treatment. Consequently the emotional component of health care becomes a highly variable and unpredictable factor since many other science-based technological factors enter into the health care equation (Phillips 1996, 140).

McQueen (2000) comments that healthcare organizations have already begun modeling themselves after customer service organizations in that patients are now being thought of and marketed to as customers or consumers of services rather than recipients of care. Mann (2005) and Bolton (2001) also make reference to shifting linguistic trends that refer to patients as clients and other symptoms of the infiltration of a 'market mentality' into the healthcare field (Mann $2005,306)$. Within this business context the efficient delivery of health care often gains primacy over effectiveness, as responses to 'patient satisfaction surveys' become a central means of evaluating the services received (Dubé and Menon 1998).

In one study, Bone (2002) argues that by calling changes in health care 'patient centered', healthcare organizations have been able to effectively deskill the labor force in order to save money. Similarly, Hunter and Smith (2007) comment that the National Health Service in Britain has shifted from a public to a commercial ethos by linking some of its operations to financial incentives Bone (2002), found that nurses tried to present a detached demeanor to keep patients from making requests that they did not have time to fulfill.

Lee-Ross (1999) reinforces this in observing that constraints on time and resources Compel National Health Service nurses to ignore all of the patients' needs (e.g., spiritual, psychological, emotional) except the physical. Nurses 
report that they are stuck in a perpetual state of tension between who they want to be as a nurse and who the work environment allows them time to be (Bone 2002; Lewis 2005).

Seventy-three percent of the nurses interviewed by Weinberg $(2003,145)$ also reported that 'they did not have time to attend to patients' emotional or psychological needs, and 65 percent stated that this lack of time happened on a weekly or more frequent basis' (Weinberg 2003).

Brunton's (2005) study of nurses in New Zealand further demonstrates found that nursing staff ignored meaningful cues from patients (often stemming from anxiety associated with cancer screening) in order to process the required number of patients so that the advanced technology they were using could be made to 'pay its way' (p. 345).

Within this business context the efficient delivery of health care often gains primacy over effectiveness, as responses to 'patient satisfaction surveys' become a central means of evaluating the services received (Dubé and Menon 1998).

\section{Theoretical framework}

In order to assess emotional labor, we have studied two fundamental aspects of emotional labor, surface-acting and deep-acting. For study these two aspects ,we have employed the theories of ; Hochschild, Ashfoeth \& Humphrey, Morris and Feldman, and Grandey. Effective factors, growing emotional labor, different approaches, can be cited the following factors:

1- Social Support: The support that Sponsored by colleagues and supervisors ave root on the level of empathy and intimacy between nurses and nurse managers from one hand, And nurses gathered themselves together on the other hand, in particular the study of social support is used Hochschild emotional approach on the one hand, and approaches to Morris and Feldman on the other .

2- Job Autonomy: Morris and Feldman , and Grandey approach pay much attention to the job autonomy influence on emotional labor . Our study is based on the approach of Morris and Feldman, on the one hand, and Grandey approach on the other hand, for measurement of job autonomy have been used approach of Morris and Feldman and Grandey approach .

3- Organizational Expectations: For measurement of organizational expectations, in this study have been used Morris \&Feldman approach on the one hand, and approach of Henderson, James and Herdman on the other.

4- Commercializing Care: Another feature affecting emotional labor is business mentality impact on Healthcare affaires influence that have been treating by Bone, Hunter, Smith, Erickson and others. For measurement of commercializing care in this study have been used Bone, Hunter, Smith and Ericsson viewpoints.

5- Organizational Characteristics: For measurement of organizational characteristics, in this study have been used Turner approach .

6- Categorizing System: For measurement of categorizing system, in this study have been used Turner approach.

7- Grounded Variables: Hochschild, Morris and Feldman, Grandey and others have emphasized the role of individual characteristics in emotional labor, In this study, the effect of gender differences and job tenure on the emotional labor has been studied.

\section{Research Methodology}

The methods used in this study is a survey .Measuring instrument for navigation, a 61 -item questionnaire that, has been done among a sample size of 315 people, including 202 female and 103 male, that were employed in eight hospitals; Erfan, Ibn Sina, Imam Khomeini, Jam, Mostafa Khomeini, payambar, Sarem and sherkate naft. The construct validity of the test instrument showed that the questions are adequate construct validity. The reliability of the questionnaire was tested using by Cronbach's alpha , that shows; the measurement tools would enjoy of appropriate reliability.

Dependent variable of study was emotional labor and the independent variables were included gender, age, total tenure, tenure at the studied hospital, job autonomy, supervisor support, coworker support, hospital expectations, commercializing care, organizational characteristics, and categorizing system.

Hypotheses of the study are:

1. There is a correlation between organizational expectations and emotional labor among nurses.

2. There is a correlation between coworker support and emotional labor among nurses.

3. There is a correlation between job autonomy and emotional labor among nurses.

4. There is a correlation between supervisor support and emotional labor among nurses. 
5. There is a correlation between commercializing care and emotional labor among nurses.

6. There is a correlation between organizational characteristics and emotional labor among nurses.

7. There is a correlation between categorizing system and emotional labor among nurses.

8. Emotional labor of nurses is vary based on gender.

9. There is a correlation between total tenure and emotional labor among nurses.

10. There is a correlation between tenure at the studied hospital and emotional labor among nurses.

11. There is a correlation between increasing age of nurses and their emotional labor.

\section{Findings}

Descriptive findings:

As Table a. shows the results of emotional labor-related variables are all more than three. Among variables, deep acting is above all variables and commercializing care is less than other variables.

Table a. The rate of emotional labor-related variables among the respondents

\begin{tabular}{|l|l|l|l|}
\hline Dependent \& independent variables & Mean & maximum & minimum \\
\hline Surface-acting & 3.1202 & 4.71 & 1.86 \\
\hline Deep-acting & 3.6005 & 4.83 & 1.50 \\
\hline Emotional dissonance & 3.0357 & 5.00 & 1.00 \\
\hline Job satisfaction & 3.1937 & 5.00 & 1.00 \\
\hline Job autonomy & 3.5952 & 5.00 & 1.00 \\
\hline Supervisor support & 3.2040 & 5.00 & 1.00 \\
\hline Coworker support & 3.5000 & 5.00 & 1.00 \\
\hline Hospital expectations & 3.2744 & 5.00 & 1.83 \\
\hline Commercializing care & 3.0197 & 5.00 & 1.00 \\
\hline Organizational characteristics & 3.2171 & 5.00 & 1.40 \\
\hline Categorizing system & 3.0040 & 5.00 & 1.00 \\
\hline Emotional labor & 3.3604 & 4.70 & 2.04 \\
\hline
\end{tabular}

The average mean years of nursing tenure is eight years and seven months, and the average mean years of nursing tenure at the studied hospital is five years and seven months.

\section{Analytical findings:}

As the research regression model is shown in Table $b$. due to the fact is that $R$ Square equal .664. That means the independent variables explained sixty-six percent of the variability in the dependent variable changes and the rest of thirty-four percent of the variance in the dependent variable changes is not explained in our analysis and is residual variance. Due to the fact that the Durbin - Watson is1.7it is assumed independence of errors in the dependent and independent variables have been considered, on the other hand, the error variables are independent of each other.

\section{Table b. Summary of Regression Model}

\begin{tabular}{|l|l|l|l|l|l|}
\hline ModeL & $R$ & R Square & Adjusted R Square & Std.Error of the Estimate & Durbin-Watson \\
\hline 1 & .815 & .664 & 652. & 29013. & 1.705 \\
\hline
\end{tabular}

Predictors: (Constant), HIRARCHI, GENDER, TENURET, SSUPPORT, COMERCIA, AUTONOMY, STRUCTUR, COSUPORT, EXPECTAT, TENUREP, AGE

Dependent Variable: ELABOR 
Table c. ANOVA Test

\begin{tabular}{|l|l|l|l|l|l|l|}
\hline ModeL & & Sum of Squares & df & Mean Square & F & Sig \\
\hline 1 & Regression & 50.135 & 11 & 4.558 & $\mathbf{5 4 . 1 4 5}$ & .000 \\
\hline & Residual & $\mathbf{2 5 . 3 3 7}$ & $\mathbf{3 0 1}$ & .084 & & \\
\hline & Total & $\mathbf{7 5 . 4 7 2}$ & $\mathbf{3 1 2}$ & & - & \\
\hline
\end{tabular}

Predictors: (Constant), HIRARCHI, GENDER, TENURET, SSUPPORT, COMERCIA, AUTONOMY, STRUCTUR, COSUPORT, EXPECTAT, TENUREP, AGE

Dependent Variable: ELABOR

As the anova table is shown in table c.; the Variant analysis in one percent alpha level is significant that refers to the linearity relationship between the independent and dependent variables that is one of the most important assumptions in regression analysis . In other words, the independent variables used in the analysis were not correlated with each other, and are not explained the same variance in the dependent variable and independent variables independent of each other.

Table d. regression coefficients, variables significance, collinearity

\begin{tabular}{|c|c|c|c|c|c|c|c|c|}
\hline \multirow[t]{2}{*}{ Model } & & \multicolumn{2}{|c|}{$\begin{array}{l}\text { Unstandardized } \\
\text { Coefficients }\end{array}$} & \multirow{2}{*}{$\begin{array}{l}\text { Standardized } \\
\text { Coefficients } \\
\text { Beta }\end{array}$} & \multirow[t]{2}{*}{$\mathrm{t}$} & \multirow[t]{2}{*}{ Sig } & \multicolumn{2}{|c|}{ Collinearity Statistics } \\
\hline & & $B$ & Std.Error & & & & Tolerance & VIF \\
\hline \multirow[t]{12}{*}{1} & (Constant) & .575 & .197 & -.321 & 2.919 & .004 & .161 & 6.202 \\
\hline & TENURET & -.025 & .006 & .154 & -3.859 & .000 & .322 & 3.102 \\
\hline & TENUREP & .015 & .006 & .142 & 2.613 & .009 & .212 & 4.710 \\
\hline & AGE & .010 & .005 & .025 & 1.956 & .051 & .976 & 1.025 \\
\hline & GENDER & .026 & .035 & .369 & .725 & .469 & .817 & 1.223 \\
\hline & AUTONOMY & .223 & .022 & .399 & 9.997 & .000 & .677 & 1.477 \\
\hline & SSUPPORT & .204 & .021 & .160 & 9.834 & .000 & .773 & 1.294 \\
\hline & COSUPPORT & .105 & .025 & .006 & 4.223 & .000 & .572 & 1.747 \\
\hline & EXPECTAT & .005 & .035 & .148 & .135 & .893 & .559 & 1.787 \\
\hline & COMERCIA & .074 & .022 & .141 & 3.306 & .001 & .807 & 1.238 \\
\hline & STRUCTUR & .097 & .026 & .100 & 3.792 & .000 & .796 & 1.256 \\
\hline & HIRARCHI & .067 & .025 & -.321 & 2.683 & .008 & .161 & 6.202 \\
\hline \multicolumn{7}{|c|}{ Sig of Tolerance and VIF } & .000 & .000 \\
\hline
\end{tabular}

Dependent Variable: ELABOR

According to the results of tests of VIF and Tolerance significant in Table d. it can be concluded that;

1. There is not multi collinearity of correlation among variables.

2. emotional labor does not depend on age and gender .

3. Hospital expectations does not correlate with emotional labor meaningfully.

Other independent variables do Correlate with dependent variable are meaningful. The total tenure, tenure at the studied hospital, job autonomy, supervisor support, commercializing care, organizational characteristics, and categorizing system, have a meaningful correlation with emotional labor, The following equation is obtained from the sum of the regression coefficients;

Emotional labor $=(-.321)+$ Total tenure $(.154)+$ Tenure at the studied hospital(.142) + Age(.025)+ gender(.369) + Job autonomy(.399)+ Supervisor support(.160)+ Coworker support(.006)+ Hospital expectations(.148)+ commercializing care(.141)+ organizational characteristics(.100)+ categorizing system(-.321)

3-4. Test hypotheses: The following hypotheses were not supported based on findings:

1. There is a correlation between organizational expectations and emotional labor among nurses.

2. Emotional labor of nurses is vary based on gender.

3.There is a correlation between increasing age of nurses and their emotional labor.

The following hypotheses were supported based on findings:

1. There is a correlation between coworker support and emotional labor among nurses. 
2. 2. There is a correlation between job autonomy and emotional labor among nurses.

3. 3.There is a correlation between supervisor support and emotional labor among nurses.

4. There is a correlation between commercializing care and emotional labor among nurses.

5. There is a correlation between organizational characteristics and emotional labor among nurses.

6. There is a correlation between categorizing system and emotional labor among nurses.

7. There is a correlation between total tenure and emotional labor among nurses.

8. There is a correlation between tenure at the studied hospital and emotional labor among nurses.

\section{Conclusion}

The points should be considered regarding the hypothesis and theoretical framework presented in the increase of emotional labor among nurses are the following ones;

1. Expectation of nurses in hospitals about doctors commands must be reduce: Most nurse complained practitioners with their own behavior and say that doctors are not properly treated with them, nurses say hospital pay attention to the physical needs of patients but neglect emotional labor about patients.

2. The level of job satisfaction was above average, but this is not enough and should be tried in order to increase job satisfaction This is obvious when we consider the importance of job satisfaction among nurses is negatively correlated with emotional exhaustion Given that the study population had a high level of emotional exhaustion recommended using such strategies; increase nurses vacation and ... to raising the level of job satisfaction to help reduce emotional exhaustion.

3. Due to the fact that the nurses in the study of hierarchical job at the hospital is not fair and this point have negative effect on doing of emotional labor on a research regression model, It is recommended to require hospitals to pay attention to the job hierarchy.

4. The results showed that, granting job autonomy increases the effectiveness of emotional labor, more compare to the other other independent variables. Therefore we recommend, more job autonomy and independence should be granted to nurses in scope of their job duties.

5. The results show an increase in the process of commercializing care at the studied hospitals, in this process, the patient's become from individual who needs to care as a customer and indeed is considered the user of health services. The prevalence of this trend may be leave irreversible effects on health care system, therefore it is recommended to stop this trend.

\section{References}

Ashforth, B.E., \& Humphrey, R. H. 1993. Emotional labor in service roles: The influence of identity. Academy of Management Review, $18,88-115$.

Bolton, Sharon C. 2001. 'Changing Faces: Nurses as Emotional Jugglers.' Sociology of Health and IIIness 23: 85-100.

Bone, Debora 2002. 'Dilemmas of Emotion Work in Nursing Under Market-Driven Health Care.' International Journal of Public Sector Management 15: 140-50.

Brotheridge, Céleste M. and Alicia A. Grandey 2002. 'Emotional Labor and Burnout:

Comparing Two Perspectives of "People Work".' Journal of Vocational Behavior 60: 17-39.

Brotheridge, Céleste M. and Raymond T. Lee 2002. 'Testing a Conservation of Resource Model of the Dynamics of Emotional Labor.' Journal of Occupational Health Psychology 7: 57-67.

Brunton, Margaret 2005. 'Emotion in Health Care: The Cost of Caring.' Journal of Health Organization and Management 19: 340-54.

Bulan, Heather F., Rebecca Erickson and Amy S. Wharton 1997. 'Doing for Others on the Job: The Affective Requirements of Service Work, Gender, and Emotional Well-Being.' Social Problems 44: 235-56.

Conrad, Charles and Kim Witte 1994. 'Is Emotional Expression Repression Oppression? Myths of Organizational Affective Regulation.' Pp. 417-28 in Social Approaches to Communication, edited by Wendy Leeds-Hurwitz. New York, NY: Guilford Press.

Davies, Celia 1995. 'Competence versus Care? Gender and Caring Work Revisited.' Acta Sociologica 38: 17-31.

Diefendorff, James M., Meredith H. Croyle and Robin H. Gosserand 2005. 'The Dimensionality and Antecedents of Emotional Labor Strategies.' Journal of Vocational Behavior 66: 339-357.

Dubé, Laurette and Kalyani Menon 1998. 'Managing Emotions: Accenting the Positive Might Not Produce the Highest Satisfaction Payoff.' Marketing Health Services 18: 35-45.

Erickson Rebecca J. \& Wendy J. C. Grove: 2008. Emotional Labor and Health Care . Sociology Compass ,Vol. 2,No.2, ,pp704-733

Erickson, Rebecca J. and Christian Ritter 2001. 'Emotional Labor, Burnout, and Inauthenticity:Does Gender Matter?' Social Psychology Quarterly 64: 146-63.

Gordon, Suzanne 1991. 'Fear of Caring: The Feminist Paradox.' American Journal of Nursing 91: 45-6, +48.

Grandey, Alicia A. 2000. 'Emotion Regulation in the Workplace: A New Way to Conceptualize Emotional Labor.' Journal of Occupational Health Psychology 5: 95-100. 
Grandey, A.A. (2003). when "the show must go on": Surface acting and deep acting as determinants of emotional exhaustion and peerrated service delivery. Academy of Management Journal, 46(1), 86-96.

Henderson, A. 2001. 'Emotional Labor and Nursing: An Under-Appreciated Aspect of Caring Work.' Nursing Inquiry 8: 130-38.

Herdman, Elizabeth A. 2004. 'Nursing in a Postemotional Society.' Nursing Philosophy 5: 95-103.

Hochschild, Arlie Russell 1979. 'Emotion Work, Feeling Rules, and Social Structure.' American Journal of Sociology 85: 551-75.

Hochschild, Arlie Russell 1983. The Managed Heart: Commercialization of Human Feeling. Berkeley, CA: University of California Press.

Hochschild, Arlie Russell 2003. 'Behind Every Great Caregiver: The Emotional Labour in Health Care.' Pp. 67-72 in Emotional and Interpersonal Dimensions of Health Services, edited by Laurette Dubé, Guylaine Ferland and Debbie S. Moskowitz. Montreal, QC: McGill-Queen's University Press.

Hunter, Billie and Pam Smith 2007. 'Emotional Labour: Just Another Buzz Word?' International Journal of Nursing Studies 44: 859-61.

James, Nicky 1989. 'Emotional Labour.' Sociological Review 37: 15-42.

Kruml, Susan M. and Deanna Geddes 2000. 'Exploring the Dimensions of Emotional Labor: The Heart of Hochschild's Work.' Management Communication Quarterly 14: 8-49.

Lewis, Patricia 2005. 'Suppression or Expression: An Exploration of Emotion Management in a Special Care Baby Unit.' Work, Employment, and Society 19: 565-81.

Lively, Kathryn 2000. 'Reciprocal Emotion Management: Working together to Maintain Stratification in Private Law Firms.' Work and Occupations 21: 32-63.

Mann, Sandi 2004. 'People Work: Emotion Management, Stress and Coping.' British Journal of Guidance and Counseling 32: $205-21$.

Mann, Sandi 2005. 'A Health-Care Model of Emotional Labour.' Journal of Health Organization and Management 19: 304-17.

McQueen, Anne C. H. 2000. 'Nurse-Patient Relationships and Partners in Hospital Care.' Journal of Clinical Nursing 9: 723-31.

Meier, Kenneth J., Sharon H. Mastracci and Kristin Wilson 2006. 'Gender and Emotional Labor in Public Organizations: An Empirical Examination of the Link to Performance.' Public Administration Review 66: 899-909.

Montgomery, Anthony J., Efharis Panagopolou, Martin de Wildt and Ellis Meenks 2006. 'Work-Family Interference, Emotional Labor, and Burnout.' Journal of Managerial Psychology 21: 36-51.

Morris, J. Andrew and Daniel C. Feldman 1996. 'The Dimensions, Antecedents, and Consequences of Emotional Labor.' Academy of Management Review 21: 986-1010.

Morris, J., \& Feldman, D. 1997. Managing emotions in the workplace. Journal of

Managerial Issues, 9, 257-274.

Phillips, Sue 1996. 'Labouring the Emotions: Expanding the Remit of Nursing Work?' Journal of Advanced Nursing 24: 139-43.

Rafaeli, Anat and Robert I. Sutton 1987. 'Expression of Emotion as Part of the Work Role.' Academy of Management Review 12: 23-37.

Shuler, Sherianne and Beverly D. Sypher 2000. 'Seeking Emotional Labor: When Managing the Heart Enhances the Work Experience.' Management Communication Quarterly 14: 50-89.

Smith, Pam 1992. The Emotional Labour of Nursing. London, UK: Macmillan Press.

Staden, Helene 1998. 'Alertness to the Needs of Others: A Study of the Emotional Labour of Caring.' Journal of Advanced Nursing 27: $147-56$.

Tumer, Jonathan H., and Jan E. Stets.( 2005). The Sociology of Emotions. Cambridge: Cambridge University Press.

Tumer, Jonathan H., and Jan E. Stets.( 2006). Handbook of the Sociology of Emotions: Springer Science \& Business Media. LLC

Weinberg, Dana Beth 2003. Code Green: Money-Driven Hospitals and the Dismantling of Nursing. Ithaca, NY: Cornell University Press.

Wharton, Amy S. 1993. 'The Affective Consequences of Service Work: Managing Emotions on the Job.' Work and Occupations 20: 20532.

Woodward, Vivien M. 1997. 'Professional Caring: A Contradiction in Terms?' Journal of Advanced Nursing 26: 999-1004. 
